\title{
Environmental Uncertainty and Flexibility
}

\author{
M. K. Nandakumar · Sanjay Jharkharia $\cdot$ \\ Abhilash Nair
}

Published online: 5 February 2013

(C) Global Institute of Flexible Systems Management 2013

Keywords Environmental uncertainty ·

Organisational flexibility - Strategic flexibility .

Performance

The economic downturn which began in 2008 resulted in a turbulent business environment making it extremely difficult for organisations to formulate and implement strategies. Business houses all over the world struggle to predict future trends because of environmental uncertainties. These uncertainties can be broadly classified into three categories as follows: (i) State uncertainties-when business environment or a particular part of it is unpredictable (Conrath 1967); (ii) Effect Uncertainty - deals with the effect of these uncertainties on a particular project or firm as a whole (Duncan 1972) and (iii) Response uncertainty—deals with the inability to gauge the consequences of choice of response (Conrath 1967; Duncan 1972). In such an environment organisations face a number of challenges like attracting and retaining talented employees, reducing the amount of uncertainties and creating a company culture suitable for facing uncertainties (Hartman 2009). While operating in such an environment organisations need to acquire capabilities which enable them to adapt quickly to changing environments. This implies that contemporary organisations need to have tremendous amount of flexibility in their operations. Flexibility helps organisations to overcome many of the challenges associated with uncertainties and improves their overall competitiveness. Furthermore flexibility is important to justify the need to invest

M. K. Nandakumar $(\bowtie) \cdot$ S. Jharkharia · A. Nair Indian Institute of Management Kozhikode, Kozhikode, India e-mail: nandakumarmk@iimk.ac.in in high gestation projects which otherwise may look financially unviable.

In an uncertain environment, achievement of sustainable competitive advantage largely depends upon an organisation's ability to change its objectives very quickly and to reconfigure strategically (Hitt et al. 1998). This type of capability is known as strategic flexibility. Evidence provided by empirical studies indicate that strategic flexibility is positively related to organisational performance (Grewal and Tansuhaj 2001; Nadkarni and Narayanan 2007; Worren et al. 2002). Findings from empirical studies also suggest that strategic flexibility facilitates greater level of innovation in organisations (e.g. Zhou and Wu 2010; Li et al. 2010). Hence uncertain environment also presents opportunities for organisations to develop their strategic flexibility which in turn helps them to promote innovation and improve performance.

The growth engines of global economy have shifted predominantly to the east where infrastructure, research and knowledge creation is a big bottleneck. Hence, in the current scenario, it is important for the developing and developed nations to understand and appreciate each other's concerns. It was in this backdrop that the Eleventh Global Conference on Flexible Systems Management (IIMK-GLOGIFT 11) was organised at Indian Institute of Management Kozhikode (IIMK) from 9th to 12th of December 2011 in association with Global Institute of Flexible Systems Management, Indian Institute of Technology, New Delhi and Stevens Institute of Technology, New Jersey. The conference provided a global forum for practitioners, policy makers, teachers, researchers and learners to share their practical experiences, knowledge and insights in the evolution, formulation and implementation of strategies and models which enable flexible enterprises to meet the changing requirements of global business. 
We have received about 120 submissions for this conference from various countries including USA, UK, Germany, Japan and Brazil. We have shortlisted 27 papers and on the basis of a double-blind review process we selected 6 papers for this special issue. We would like to thank Prof. Debashis Chatterjee, Director Indian Institute of Management Kozhikode for providing us whole-hearted support to organise this conference at IIMK campus. We are also grateful to Prof. Sushil, Founder President of GIFT Society for giving us an opportunity to organise this conference. We are also thankful to all the reviewers who have helped us in the review process for this special issue.

Acknowledgments The editors are thankful to Ms K. Aarathi for the editorial support provided for compiling this special issue.

\section{References}

Conrath, D. W. (1967). Organizational decision making behaviour under varying conditions of uncertainty. Management Science, $13,487-500$

Duncan, R. B. (1972). Characteristics of organisational environments and perceived environmental uncertainty. Administrative Science Quarterly, 17, 313-327.

Grewal, R., \& Tansuhaj, P. (2001). Building organizational capabilities for managing economic crisis: The role of market orientation and strategic flexibility. Journal of Marketing, 65(2), $67-80$.

Hartman, N. A. (2009) Sure ways to tackle uncertainty in tough times. Financial Times, 5th Feb. Retrieved from http://www.ft.com.

Hitt, M., Keats, B., \& DeMarie, S. (1998). Navigating in the new competitive landscape: Building strategic flexibility and competitive advantage in the 21st century. Academy of Management Executive, 12(4), 22-43.

Li, Y., Su, Z., \& Liu, Y. (2010). Can strategic flexibility help firms profit from product innovation? Technovation, 30(5-6), 300-309.

Nadkarni, S., \& Narayanan, V. K. (2007). Strategic schemas, strategic flexibility, and firm performance: The moderating role of industry clockspeed. Strategic Management Journal, 28, 243-270.

Worren, N., Moore, K., \& Cardona, P. (2002). Modularity, strategic flexibility and firm performance: A study of the home appliance industry. Strategic Management Journal, 23, 1123-1140.

Zhou, K. Z., \& Wu, F. (2010). Technological capability, strategic flexibility, and product innovation. Strategic Management Journal, 31, 547-561.

\section{Author Biographies}

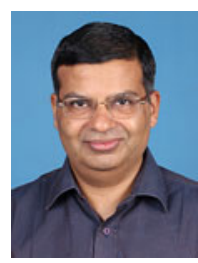

Dr. M.K. Nandakumar is the Chairman of International Exchange Programme at Indian Institute of Management Kozhikode (IIMK). He is also the Chairman of Strategic Management Area at IIMK. He obtained his $\mathrm{PhD}$ from Middlesex University London. Under his chairmanship the international exchange programme at IIMK has developed very rapidly. He teaches a number of courses at the MBA and Doctoral levels and also for the Executive Education Programmes. Dr. Nandakumar has successfully coordinated the Association of MBAs (AMBA) accreditation project at IIMK. He has worked as Lecturer at both Middlesex University Business School and East London University Business School. He has also worked as Marketing Manager and Area Manager in reputable organizations. He has published a few papers in leading academic journals and presented a number of papers for major international conferences. Dr. Nandakumar's paper published in Management Decision has been chosen as a Highly Commended Award Winner at the Literati Network Awards for Excellence 2011. He has co-chaired two international conferences namely Eleventh Global Conference on Flexible Systems Management (IIMK-GLOGIFT 11) and the International Conference on Global Strategies for an Emergent India. He is a guest editor of an issue of International Studies of Management and Organization.

Dr. Sanjay Jharkharia is Professor of Operations Management at Indian Institute of Management Kozhikode (India) and holds PhD. from Indian Institute of Technology Delhi. He has published research papers in several journals including Omega: International Journal of Management Science, International Journal of Operations and Production Management and Supply Chain Management: An International Journal. His current research interests include Multi-criteria decision making, operations strategy and cold supply chain.

Dr. Abhilash Nair is an Assistant Professor in the Finance, Accounting and Control Area. He completed his doctoral studies at the Department of Humanities and Social Sciences, Indian Institute of Technology Bombay. During his doctoral work, he was a Visiting Scholar at the Haas School of Business, University of California at Berkeley as a Fulbright Junior Research Fellow. He has published in refereed Indian and International journals and has presented research papers at several Indian and International conferences. Two of his conference papers have received the best paper awards at the respective conferences. One at the Sixth Annual Capital Market Conference organized by Indian Institute of Capital Markets, Bombay and another at the Second International conference on Globalisation: Opportunities and Challenges organized by IBS Ahmedabad. Moreover, on policy related issues he contributes to Business periodicals such Economic times and Business world. His area of research interest is Financial Economics in general and Asset Pricing Models in particular. Currently, he is working on issues related to valuation of human capital and application of real options to price take out financing contracts. Recently, he has published a paper in the International Research Journal of Finance and Economics and another paper in Applied Financial Economics a Taylor and Francis Journal. 